\title{
КОГНИТИВНЫЕ И ПРАГМАТИЧЕСКИЕ ОСОБЕННОСТИ УКРАИНСКОГО ВОЕННОГО ЮМОРИСТИЧЕСКОГО ДИСКУРСА СОЦИАЛЬНЫХ СЕТЕЙ
}

\author{
Тетяна Храбан \\ xraban.tatyana@gmail.com \\ Национальный авиационный университет, Украина \\ Игор Храбан \\ khraban728@gmail.com \\ Межрегиональная академия управления персоналом, Украина
}

\section{Received October 1, 2019; Revised December 6, 2019; Accepted December 22, 2019}

Анотація. Дослідження гумору й сміху здійснюють у багатьох галузях когнітивної лінгвістики та психології, психо- та соціолінгвістики. Гумор розглядають як позитивну емоцію, викликану когнітивними процесами оцінки комічних висловлень у різних соціальних ситуаціях (Martin, 2007). Мета дослідження полягає в установленні когнітивнопрагматичних характеристик українського військового гумористичного дискурсу в соціальних мережах. Для досягнення поставленої мети застосовано лінгвістичні методи дискурс-аналізу, контекстуального та інтуїтивно-логічного інтерпретативного аналізу, а також психолінгвістичний метод контент-аналізу. Вивчення грунтується на вибарному корпусі інтернет мемів та комічних коментарів, взятих із соціальних мереж і поділених на тематичні групи. Результати дослідження засвідчили, конструктивний гумор, що охоплює 47\% всіх проаналізованих текстів, має тенденцію до частотнішого використання, порівняно 3 іншими психолінгвістичними типами. Його прагматична мета - здійснити позитивний уплив на процес формування групи через його здатність полегшувати міжособистісні стосунки між комунікантами на основі позитивних емоцій. Самопідтримувальний гумор, що зафіксовано в 33\% випадків, демонструє вміння мовця зберігати жартівливий погляд на будь-які життєві події. «Чорний» і зневажливий гумор менш поширені у дискурсі українських військових, складаючи разом $20 \%$ усіх прикладів.

Ключові слова: гумор, український військовий гумористичний дискурс, сочіальні мережі.

Khraban, Tetyana; Khraban, Ihor. Cognitive and Pragmatic Features of the Ukrainian Army Humorous Discourse in Social Media.

Abstract. Research on humor and laughter is carried out in many areas of cognitive linguistics and psychology, psycho- and sociolinguistics. Humor is viewed as a positive emotion evoked by the cognitive processes of evaluating comical utterances in various social settings (Martin, 2007). The aim of the paper is explore the cognitive and pragmatic aspects of the Ukrainian military humorous discourse in social media. To this end, linguistic methods of discourse analysis, contextual and intuitive logical interpretative analysis, and a psycholinguistic method of content analysis were applied. The study is based on the selected corpus of Internet memes and amusing comments taken from social media and further divided into thematic groups. The results of the study indicate that constructive humor comprising 47 per cent of the analyzed texts tend to be more popular than other psycholinguistic types. Its pragmatic purpose is to provide

(C) Храбан Тетяна, Храбан Игор, 2019. This is an Open Access article distributed under the terms and conditions of the Creative Commons Attribution 4.0 International Licence (http://creativecommons.org/ licenses/by/4.0).

East European Journal of Psycholinguistics, 6(2), 21-31. https://doi.org/10.5281/zenodo.3637710 
a positive impact on the process of group formation due to its capacity to facilitate interpersonal contacts between individuals by evoking positive emotions. Self-sustaining humor embracing 33 per cent of the analyzed texts manifests the speaker's ability to preserve a humorous viewpoint of any life events. "Black humor" and derogatory humor are less frequent in the Ukrainian Army discourse of social media covering only 20 per cent of all analyzed texts.

Keywords: humor, Ukrainian Army humorous discourse, social media.

\section{1. Введение}

Огромное количество работ посвящено изучению различных аспектов юмора, но появление таких организаций как «Американская ассоциация по изучению юмора» (American Humor Studies Association) и «Международное общество исследования юмора» (International Society for Humor Studies) свидетельствует о том, что эта тематика продолжает вызывать интерес ученых. Юмор охватывает многие стороны жизни человека, поэтому не случайно исследование его в современной научной парадигме становится всё более междисциплинарным. Так, в лингвистике и психолингвистике накоплен большой объём теоретических и эмпирических знаний, касающихся юмора, и сейчас на первый план выходит проблема соотнесения лингвистических результатов исследований с более общими достижениями в познании действительности. Такая задача согласуется с «когнитивной парадигмой, в рамках которой установлено, что аспекты языка регулируются или мотивируются когнитивными параметрами, основанными на человеческом опыте и “вложенными” в реальный контекст» (Кулинич, 2000). В свою очередь, благодаря когнитивному подходу, согласно взгляду Е. Широких (2015), исходящему из тезиса о параллелизме лингвальных и мыслительных процессов, языковые структуры способны отражать не структуру окружающего мира, а когнитивного существования человека. Этот подход «предлагает ещё более широкую перспективу интерпретации комического высказывания - на уровне дискурса в совокупности с его прагматическими, социокультурными и психологическими характеристиками» (Широких, 2015, c. 145).

Такой подход актуален для исследования параметров юмора украинских военных, обусловленного социальным, политическим и культурным контекстом. При этом особое значение приобретает психолингвистическое направление современного когнитивизма, использующее знания о внимании и памяти, распознавании образов, операциях мыслительной деятельности (сравнение, отождествление, умозаключение, формирование концептов), то есть лингвистические знания рассматриваются в единстве с психологическими (Евстафьева, 2006; Lopez \& Vaid, 2017). В данном контексте О. Федорова говорит о начале нового этапа развития междисциплинарной интеграции между психологией и лингвистикой, «который характеризуется созданием новых кросс- и даже интердисциплинарных связей на новом уровне взаимодействия - между психолингвистикой и когнитивной лингвистикой» (Федорова, 2014, с. 18). 
Выбор юмора украинских военных в качестве объекта исследования согласуется и с социолингвистическим подходом, акцентирующим внимание на общественной обусловленности возникновения, развития и функционирования языка, воздействии общества на язык и языка на общество, соотношении языка и социальной структуры, а также на социальном расслоение языка (Квеско, 2007, с. 61). Пребывание личности в воинском коллективе приводит к формированию своеобразного стиля юмористического поведения, качественными показателями которого выступают, к примеру, предпочтения тематики юмористических высказываний, понимание содержащей юмор информации, способность к продуцированию юмора (Квасник, 2012, с. 84). С другой стороны, социолингвистический подход способствует выявлению социальной конструкции всех смыслов, а также изучению интерактивного взаимодействия языка и социальной среды как совокупности социально-языковых и социально-деятельностных коммуникаций в образовании определенной социальной корпоративной среды общества (Квеско, 2007, с. 66). Подытоживая вышесказанное, можно утверждать, что социолингвистический подход дает возможность описать корреляцию речевого поведения украинских военных с их социальным статусом и спецификой профессии. Таким образом, подход к юмору как к уникальной, сложной многомерной структуры, исследование которой требует синтеза различных подходов, составляет актуальность данной статьи.

Различные аспекты юмора довольно широко и глубоко исследованы в философии, лингвистике, культурологии, социологии и психологии. Так, в работе Skryl \& Sharun (2019) изучено языковую смеющуюся личность (Ното Ridens) в британской литературе в рамках теории антропоцентризма. О. Гудзенко (2014) очерчивает концептуальные основы исследования смеховой культуры как модуса социокультурных трансформаций украинского общества. А. Квасник (2012) рассматривает изучение когнитивного компонента юмора в качестве механизма юмористического переживания, в то время как С. Помирча, М. Яценко (2013) характеризуют юмор в романе А. Ильченко как национальную черту украинцев. Н. Поневчинська (2013) проанализировала возможности применения лингвокогнитивних теорий для объяснения механизма создания юмористического эффекта.

\section{2. Методы исследования}

Несмотря на значительное количество работ, посвященных исследованию комического, не было уделено должного внимания глубинным механизмам, происходящим в сознании личности в процессе продуцирования и восприятия юмора. Цель настоящего исследования заключается в установлении когнитивно-прагматических характеристик украинского военного юмористического дискурса в интернет-коммуникации.

Для достижения поставленной цели считаем оправданным использование таких лингвистических методов исследования: дискурс-анализ, контекстуального и интуитивно-логического интерпретационного анализа, психолингвисти- 
ческий метод контент-анализа. Материалом исследования послужили интернет-мемы украинского сектора социальных сетей и комментарии к ним.

\section{3. Обсуждение результатов}

Для данной статьи актуальным является определение юмора, предложенное Martin (2007), в рамках которого актуализируется психологический аспект этого понятия: юмор - это, по сути, положительная эмоция, вызываемая в социальных контекстах когнитивным процессом оценки шутливого, несерьезного высказывания. В социальных взаимодействиях юмор приобретает много различных форм, включая «консервированные шутки», спонтанные шутки и непреднамеренные забавные высказывания и действия (Martin, 2007), а также дефиниция юмора, предложенная Chlopicki \& Brzozowska (2017), в котором юмор трактуется как конструкт, зависящий от социокультурного контекста и имеющий собственную структуру и функциональные особенности. Рассматривая юмор как систему знаний, убеждений и привычек, с помощью которой малая группа определяет себя и позволяет своим членам чувствовать принадлежность к группе и сплоченность (Martin, 2007), и в которой юмор в форме дружеского поддразнивания, забавных прозвищ, понятных лишь членам группы шуток и собственного сленга, может вносить вклад в идеокультуру группы, представляя ее членам способ создания общей реальности и ощущение осмысленности, создавать общую идентичность и таким образом усиливать чувство сплоченности, можем говорить про существование смеховой культуры украинских военных. Созданию и распространению этой смеховой культуры в большой мере способствуют современные информационно-коммуникативные технологии. В рамках интернета уникальность юмора состоит в том, что подобная коммуникация устремляется к увеличению числа участников и не ограничивается только диалогом из двух субъектов (Гудзенко, 2014, с. 164). Это позволяет исследовать не отдельно взятый юмористический текст, а юмористический дискурс, который, по мнению Хёйзинга (1997), представляет собой игру как на когнитивном, так и на языковом уровне, целостную форму речи, характеризующуюся несерьезной тональностью общения, игровым переосмыслением актуальных концептов и стереотипов и преследующую развлекательную цель. В целом, назначение юмористического дискурса - игра средствами языка, нормами и стереотипами, предполагающая не только развлечение и смех, но и освобождение человека от природного и социального детерминизма.

В данном исследовании для более продуктивного анализа юмористического дискурса украинских военных выборка интернет-мемов и комментариев до них, включающих в себя смеховой компонент, разделена на тематические группы (ТГ).

1. «Черный юмор», проявляющийся в экспликации темы насилия и составляющий 7 \% от репрезентативной выборки. «Черный юмор» проявляет себя на уровне семантики, стилистики и прагматики особым образом, обретает 
некие специфические черты, которые вызывают не только смех, но придают ему определенные идейно-эстетические функции (Кириченко, 2015, с. 102). Тема насилия, являясь доминантной в «черном юморе» украинского военного юмористического дискурса, определяет структуру вербального компонента интернет-мемов, объясняет выбор тем и позволяет наиболее очевидно реализовать идейную направленность. Прежде всего необходимо отметить, что мотив насилия появился в украинском военном юмористическом дискурсе как одна из форм реакции на специфику военно-политической ситуации, сложившейся в Украине. Жизнь в состоянии войны порождает углубление культурной дифференциации, поиска и защиты собственной идентичности, что особенно проявляется на языковом уровне в создании оппозиции «свой враг»: На вулицуі Левищького у Львові питають у діда: "Як кращуе попасти в російське консульство?». Він трохи подумав $i$ відповідає: «Мабуть, 3 гранатомета»; «Йозефе, ти бачиш зосередження сил супротивника?»- «Так точно, обер-лейтенанте Валерій, спостерігаю, здається, вони намагаються грати в футбол поліном.» - «Йозефе, я вважаю, щзо треба подарувати изим наркоманам м'яча, або, хоча б, качан капусти, а то на цее боляче дивитись.»«При всій повазі, пане обер-лейтенанте Валерій, війна зробила Вас жалісливим. Ви б ще запропонували розмінувати їм поле, на якому вони грають». К лингвистическим средствам манифестации мотива насилия также относится выражение угрозы: Пуля очень многое меняет в голове, даже если nопадает в заднииу. На образно-символическом уровне мотив насилия реализован при помощи удачно выбранных образов оружия противопехотной мины, снайперской винтовки. Объединение в интернет-меме визуальных компонентов с изображением оружия и вербальных компонентов позволяет полностью изменить значение фразеологизмов (в одно ухо влетело, в другое - вылетело; одна нога здесь, другая - там), наполнив их такими семантическими компонентами как «опасность», «смерть», «война».

2. Уничижительный юмор, составляющий $13 \%$ от репрезентативной выборки. Уничижительный юмор в дискурсе украинских военных направлен на осмеяние стиля мышления, отличительного от мышления военных кадров. Во-первых, «военное мышление является специфичным видом военных кадров, так как оно осуществляется в условиях специфично опасной для жизни практики» (Сигида, 2006, с. 147), а во-вторых, стандарты военного мышления коллективистского типа отличается от стандартов мышления индивидуалистского общества. Сейчас, когда в обществе усиливается состояние усталости от войны, в частности в коллективно-психологическом измерении, военные, особенно те, кто принимал участие в боевых действиях, часто рассматривают гражданское население как группу индивидов, ставящие свои интересы выше государственных: Збори резервістів 2019 рік: "Да ми кращі!!»: "Я тоже лук хочу!», «Зачем мне лук? Я хочу АГС! », «А автик скоро дадут?», «Товариш майор, а молоток обов'язково?», "В мене койка коротка!», "Зачем учиться, что я там ещуе не знаю?», "Лично мне форма очень идет!»; И забыли самого главного супергероя Аватармена - синее 
сущуество, которое пустой бутылкой водки останавливает 7 танков, а от его перегара падает весь наряд патруля ВСП! Специфика уничижительного юмора в дискурсе украинских военных проявляется в его прагматической направленности: он не преследует цель унизить, вызвать обиду, раздражение или гнев, его задача - обратить внимание общества, что служба в армии - это тяжелый и недооцененный труд, достойный уважения и благодарности: Вам не подобаються Вамі житлові умови? Ви незадоволені високими тарифами на опалення та гарячу воду? Ви втомилися від суєти великого місия? Туристична компанія «ООС» пропонує Вам релакс-тур в живописні місия Луганшини та Донеччини; Порошенко посетил ООС и остался недовольный; «Почему на передовой до сих пор нет ни одного магазина «Рошен»?». Таким образом, прагматическая направленность такого вида юмора носит защитный характер.

К уничижительному юмору в дискурсе украинских военных следует также отнести насмешки над женщинами, который проходят военную службу или работают в этой сфере: «Свєта, ти розумієш, щзо нас зараз знімають?»«Я в курсі, але ж нам казали, щуо ми тільки в броніках постоймо. Тепер треба щчось нажимати.» - «А де він вмикається?» - «Не знаю, але тут якісь ичифри. Ти Морзе знаєш?» - «Кого?» - «Азбуку?» - «А, да.»;; сказочный снайпер (визуальный компонент интернет-мема - девушка, позирующая со снайперской винтовкой и закрывшая тот глаз, которым она должна прицеливаться).

Причину появления уничижительного юмора по отношению к женщинам в дискурсе украинских военных следует искать, по нашему мнению, в истории украинского казачества: согласно обычаю, запорожцы не допускали на Сечь женщин, а предоставление приюта женщинам, не исключая матери, сестры или дочери, возле Запорожской Сечи считалось у казаков уголовным преступлением и сурово наказывалось. Среди запорожцев существовало поверье: как нога женщины ступить на землю крепости, наступит конец жизни всего Запорожья, поэтому запрет на появление женщины в крепости так тщательно соблюдался (Пищанская, 2014). Несмотря на то, что в Украине вступил в силу закон о гендерном равенстве, закрепляющий принцип, согласно которому женщины проходят военную службу на равных началах с мужчинами, включая равный доступ к должностям и воинским званиям и равный объем ответственности при исполнении обязанностей военной службы, следует отметить сохранение исторически сложившегося в украинском обществе предубеждения против службы женщин в армии.

3. Самоподдерживающий юмор, составляющий 33 \% от репрезентативной выборки, направлен на себя и его использование применительно к юмористическому дискурса украинских военных предполагает эмоциональную устойчивость, обладание навыками ориентации и адаптации в быстро меняющемся информационном пространстве. Самоподдерживающий юмор манифестирует умение сохранять юмористический взгляд на жизнь, даже когда другие не разделяют этот взгляд, придерживаться юмористической 
точки зрения на любые события. Такой стиль юмора, как правило, используется, когда человек узнаёт о чём-то неприятном или попадает в такую ситуацию, которая выводит его из состояния равновесия (Буенок, 2012, с. 62). Поскольку армия - это социальный институт общества, в юмористическом дискурсе украинских военных, как в зеркале, отражаются все болезненные процессы и противоречия, существующие в армии: протекционизм, бюрократизм и формализм, социально-правовая незащищенность военнослужащих всех категорий, низкий уровень их материального обеспечения, падение престижа армии и военной дисциплины (Афонин, 2014, с. 57-58). Основное содержание текстов самоподдерживающего юмора - отношения начальствования и подчинения: «Пане сержант, а крокодили літають?»«Солдат, ти щзо, «перегрівся»?» - «А командир нам казав, щзо літають.»«Кхм... Значить так: літають, але дуже низько $i$ лише у воєнний час. Зрозумів?»; «Вам було страшно в АТО?» - «Так.» - «Чого боялись найбільше?» - «Долбойобів.»; "Товариш капітан, фсьо!!!» - «Ну щзо, зробив?» - «Да!!! Зламав!!!». Отражая специфику военной службы, самоподдерживающий юмор становится понятным только тем, кто находится внутри этой системы или когда-то соприкасался с ней. Например, интернетмем с вербальным компонентом: Де б ви не були, щзоб ви не робили - завжди знайдеться той, хто прийде перевірити ваш план евакуації (визуальный компонент акцентирует внимание на схеме под названием «План евакуації», где присутствует схематическое изображение кругового движения с криками «A-a-a-a-a-a-a...» как символа паники) - отражает такую проблему в украинской армии, как несообразность оценки боеспособности воинских частей, которая определяется не по результатам ее реальной боеготовности и подготовки, а прежде всего по административным и хозяйственным показателям, по состоянию отчетности. Вербальный компонент интернет-мема - Если Вам не нравится место, где Bы находитесь, смените его, Вы же не дерево - акцентирует существующую в настоящее время сложную ситуацию, касающуюся увольнения из рядов армии. Отток кадров, порожденный отсутствием эффективной системы создания мотивации службы в армии, пытаются не допустить любой ценой. Форма и содержание таких трудовых отношений службы в армии являются непонятными для гражданских лиц.

Прагматическим направлением самоподдерживающего юмора в дискурсе украинских военных является стабилизирующая функция, которая связана с потребностью смягчить переживание фрустрации, сопряженной с обнаружением собственной несостоятельности, потребность в самопринятии, утверждении и сохранении (восстановлении) идентичности, преодолении внутреннего противоречивого отношения к себе и своим личностным качествам на основе постижения своего природного характера, здоровых основ «Я» (Копытин, 2014).

4. Конструктивный юмор, оставляющий $47 \%$ от репрезентативной выборки. Прагматическим направлением конструктивного юмора становится его положительное влияние на процесс формирования группы благодаря его 
способности облегчать межличностные контакты и вызывать положительные эмоции. Спонтанные шутки часто сопровождаются юмористическими образами, служащими развитию группы как живого, неформального коллектива людей, объединенных не внешними обязательствами, но общими интересами и значимой деятельностью (Копытин, 2014). Конструктивный юмор, в свою очередь, можно условно поделить на подгруппы:

а) юмор, содержащий эмоционально нейтральные раздражители (43\%). Такой юмор отражает типологию мышления (поведения) военнослужащего на базе имитационной модели жизнедеятельности индивида в конкретных условиях (типичных или экстремальных), которое зависит от внешних факторов, характеризующих армию как социальный институт: Вислів «розмір не має значення» придумали люди, котрі видають взуття; "А де видаються водійські права на керування танком?» - «Та керуйте так, хто Вас зупинить?»; Хозяюшке на заметку: куриные яйца хорошо хранить/переносить в таре от ручных гранат РГД-5; «А що вам каже ваш тато?» - «Завжди стався до зброї як до зарядженої. Не спрямовуй туди, куди не хочеш стріляти. Ніколи не чіпай гачок доки не готовий стріляти. Перевіри, шзо перед мішенню $і$ за нею»; «В армии три проблемьл: 1) удержать лейтенанта на службе; 2) майора в семье; 3) отправить полковника на пенсию».

Следует отметить появление в юмористическом дискурсе украинских военных типичных комических образов, например, «Леха из пехоты»: «Леха, не молчи, скажи хоть что-нибудь!» (визуальный компонент - военный, находящийся полностью под водой, но держащий свое оружие над поверхностью так, что видно только кисти его рук); «Льоха, де ми? А давай y Славика спитаємо... Славик усю ніч на планшеті в танчики грав... Славик казав, щзо і так дорогу знає... правда, Славик?»; «Миколай, Ви не знаходити в цььому бульйоні нотки розмарину?» - «Льоха, мені казали, щзо ти - чудило, але ж не стільки!» (визуальный компонент - двое военных обедают, лежа на животах, прячась от дождя под танком).

Чувство юмора традиционно является ценным и востребованным у военнослужащих, может даже культивироваться в их субкультуре, и в какойто степени становится маркером их профессиональной самоидентификации, например, связистов (Главный девиз связистов: громче крикнул - дальше сльишно!), разведчиков (... надо ховаться!!! Вон, даже нашу старуху в военную разведку забрали! (визуальный компонент изображает Сову персонаж мультфильма «Винни Пух», а сова является символом военной разведки Украины), служащих военкоматов (Принять мужчину таким, как он есть, может только военкомат), артиллеристов ( $K$ черту таких друзей, которые вспоминают про тебя только тогда, когда им нужна твоя артиллерийская поддержка), снайперов (Человек с ружьем всегда найдет свою изель в жизни) и т.П.;

б) положительный, жизнеутверждающий юмор, содержащий эмоционально позитивные раздражители (4\%): Не расстраивайся, если тебя 
никто не замечает! Из тебя может выйти отличный снайпер! Завжди май план Б (визуальный компонент - военный с рогаткой); Все, что не убивает меня, может не успеть удрать.

Жизнеутверждающий юмор вызывает ощущение того, что человек может справиться с любыми трудностями и в полной мере насладиться жизнью, поэтому не случайно, что именно такой вид юмор используется в рекламе армии Украины, которая распространяется в социальных сетях: $B$ перспективну компанію потрібні оператори ПК (здесь используется омонимия как механизм языковой игры - ПК может означать пехотный пулемет и персональный компьютер); Будь собою, крім випадків, коли ти можеш бути танкістом.

\section{4. Выводы}

Анализ юмористического дискурса военных в интернет-коммуникации доказал, что наиболее востребованным является конструктивный юмор, прагматическое направление которого - формирования групповой идентичности. Прагматическим направлением самоподдерживающего юмора в дискурсе украинских военных является поддерживающая функция потребность смягчить переживание фрустрации. Прагматическая направленность уничижительного юмора носит защитный характер, его цель обратить внимание общества, что служба в армии - это тяжелый и недооцененный труд, достойный уважения и благодарности. К уничижительному юмору в дискурсе украинских военных следует также отнести насмешки над женщинами, проходящими военную службу или работающими в этой сфере. Причину появления уничижительного юмора по отношению к женщинам в армии следует искать в сохранении стереотипов, берущих свое начало в традициях Запорожской Сечи. Тема насилия, являясь доминантной в «черном юморе» украинского военного юмористического дискурса, позволяет наиболее очевидно реализовать его идейную направленность.

\section{Литература \\ References}

Афонин Э. А. Становление Вооруженных Сил Украины: социальные и социальнопсихологические проблемы. К.: НТЦ «Психея», 2014.

Буенок А. Г. Психологический анализ предпочитаемых стилей юмора в управленческой деятельности // Сибирский психологический журнал. 2012, № 4. С. 60-64.

Chlopicki, W. \& Brzozowska, D. (2017). Humorous Discourse. Berlin: Walter de Gruyter.

Гудзенко О. 3. Сміхова культура як модус соціокультурних трансформацій українського суспільства // Грані. 2014. № 12. С. 162-166.

Евстафьева М. А. Когнитивные стратегии языковой игры: на материале русскоязычных и англоязычных анекдотов: дисс. ... канд. филол. наук. Калининград, 2006.

Квасник А. В. Исследование особенностей когнитивного компонента юмора // Наука i освіта. 2012, № 9. С. 84-87. 
Квеско Р. Б., Ванина И. Л., Квеско С. Б., Чубик А. П., Бухтояров С. В., Емельянова Н. Е. Социолингвистическая коммуникация как элемент общественных отношений // Известия Томского политехнического университета. 2007, № 7. С. 61-67.

Кириченко Д. А. Образно-символическая интерпретация насилия в пьесах Мартина МакДонаха // Филологические науки. Вопросы теории и практики. 2015. Вып. 2, № 44. C. 101-105.

Копытин А. И., Лебедев А. А. Юмор в рисунках ветеранов войн в ходе клинической системной арт-терапии // Медицинская психология в России. 2014. Вып. 3, № 26. Retrieved from http://www.mprj.ru/archiv_global/2014_3_26/nomer/nomer02.php.

Кулинич М. А. Семантика, структура и прагматика англоязычного юмора: Автореф. дисс. ... докт. культурол. М.: Моск. пед. гос. ун-т., 2000.

Lopez, B.G. \& Vaid, J. (2017). Psycholinguistic approaches to humor. In S. Attardo (Ed.), The Routledge Handbook of Language and Humor (pp. 267-281). New York: Routledge.

Martin, R. (2007). The Psychology of Humor. An Integrative Approach. Burlington, MA: Elsevier Academic Press.

Піщанська В. М. Жінка в культурі українського козацтва // Культура України. 2014. Вип. 45. C. 47-53.

Помирча С. В., Яценко М. О. Вербалізація гумору як національної риси українців (за романом О. Ільченка «Козацькому роду нема переводу...») // Лінгвістика. 2013, № 1 . C. 151-157.

Поневчинська Н. В. Когнітивний аспект дослідження гумору (на матеріалі англомовних епіграм) // Вісник Луганського національного університету імені Тараса Шевченка // Філологічні науки. 2013. Вип. 14, №1. С. 64-69.

Сигида Н. А., Добряков Е. И. Военное мышление и коллективистическое общество // Сибирский журнал науки и технологий, 2006, С. 146-151.

Skryl, O. \& Sharun, Y. (2019). Linguistic Personality of Homo Ridens. Psycholinguistics, 25(2), 273-289.

Федорова О. В. Психолингвистика vs. когнитивная лингвистика на карте современной когнитивной науки // Социо- и психолингвистические исследования. 2014, № 2. С. 7 20.

Хёйзинга Й. Ноmo Ludens; Статьи по истории культуры. М.: Прогресс-Традиция, 1997. Retrieved from https://www.gumer.info > bibliotek_Buks > Culture > Heiz.

Широких Е. А. Прецедентные феномены в англоязычном юмористическом дискурсе // Широких Е. А. Прецедентные феномены в англоязычном юмористическом дискурсе // Вестник Удмуртского университета. История и филология. 2015, № 25, С. 145-150.

\section{References (translated and transliterated)}

Afonin, E`.A. (2014). Stanovlenie Vooruzhennykh Sil Ukrainy: soczialnyie $i$ sotsialnopsikhologicheskie problemy [The Development of the Armed Forces of Ukraine: Social and Socio-psychological issues]. Kyiv: Psikheya Publishers.

Buenok, A. G. (2012). Psikhologicheskiy analiz predpochitaemykh stilei yumora v upravlencheskoy deyatelnosti [Psychological analysis of preferred styles of humor in management]. Sibirskyj Psikhologicheskiy Zhurnal, 45, 60-64.

Chlopicki, W. \& Brzozowska, D. (2017). Humorous Discourse. Berlin: Walter de Gruyter.

Gudzenko, O.Z. (2014). Smikhova kultura yak modus sotsiokulturnykh transformatsiy ukrayinskoho suspilstva [The humorous culture as a mode of socio-cultural transformation of Ukrainian society]. Grani, 12, 162-166.

Evstafyeva, M. A. (2006). Kognitivnyie strategii yazykovoi igry: na materiale russkoyazychnykh $i$ angloyazychnykh anekdotov [Cognitive strategies of a language game: based on Russian and English-language anecdotes]. Ph.D. dissertation. Kaliningrad. 
Kvasnik, A. V. (2012). Issledovanie osobennostei kognitivnogo komponenta yumora. [Study of the cognitive component of humor]. Nauka i Osvita, 9, 84-87.

Kvesko, R. B., Vanina, I. L., Kvesko, S. B., Chubik, A. P., Bukhtoyarov, S. V., Emelyanova, N. E. (2007). Sotsiolingvisticheskaya kommunikatsiya kak element obshhestvennykh otnosheniy [Sociolinguistic communication as an element of social relations]. Izvestiya Tomskogo politekhnicheskogo universiteta, 7, 61-67.

Kirichenko, D. A. (2015). Obrazno-simvolicheskaya interpretatsiya nasiliya v piesakh Martina McDonagh [The figurative and symbolic interpretation of violence in the plays of Martin McDonagh]. Filologicheskie Nauki. Voprosy Teorii i Praktiki, 2(44), 101-105.

Kopytin, A. I., Lebedev, A. A. (2014). Yumor v risunkakh veteranov vojn v khode klinicheskoy sistemnoy art-terapii [Humor in the war veterans' drawings during clinical systemic art therapy]. Mediczinskaya Psikhologiya $v$ Rossii, 3(26). Retrieved from http://www.mprj.ru/archiv_global/2014_3_26/nomer/nomer02.php

Kulinich, M. A. (2000). Semantika, struktura i pragmatika angloyazychnogo yumora [Semantics, Structure, and Pragmatics of English-language Humor]. Summary of the Doctor of Cultural Sciences Dissertation. Moscow: Moscow State Pedagogical University.

Lopez, B.G. \& Vaid, J. (2017). Psycholinguistic approaches to humor. In S. Attardo (Ed.), The Routledge Handbook of Language and Humor (pp. 267-281). New York: Routledge.

Martin, R. (2007). The Psychology of Humor. An Integrative Approach. Burlington, MA: Elsevier Academic Press.

Pishhans`ka, V. M. (2014). Zhinka v kul'turi ukrayins`kogo kozacztva [Woman in the culture of Ukrainian Cossacks]. Kultura Ukrayiny, 45, 47-53.

Pomyrcha, S. V., Yatsenko, M. O. (2013). Verbalizatsiya gumoru yak natsionalnoyi rysy ukrayintsiv [The verbalization of humor as a national trait of Ukrainians]. Lingvistyka, 1, 151-157.

Ponevchynska, N. V. (2013). Kognityvnyi aspekt doslidzhennya humoru [Cognitive aspect of the study of humor]. Visnyk Luhanskoho Natsionalnoho Universytetu imeni Tarasa Shevchenka. Filologichni Nauky, 14(1), 64-69.

Sigida, N. A., Dobryakov, E. I. (2006). Voennoe myshlenie i kollektivisticheskoe obshhestvo [Military thinking and collectivist society]. Sibirskij Zhurnal Nauki i Tekhnologij, 146-151.

Skryl, O. \& Sharun, Y. (2019). Linguistic Personality of Homo Ridens. Psycholinguistics, 25(2), 273-289.

Fedorova, O. V. (2014). Psikholingvistika vs. kognitivnaya lingvistika na karte sovremennoj kognitivnoj nauki [Psycholinguistics vs. cognitive linguistics on the map of modern cognitive science]. Soczio- i Psikholingvisticheskie Issledovaniya, 2, 7-20.

Khyojzinga, J. (1997). Homo Ludens; Stat`i po istorii kultury` [Homo Ludens: Articles on the history of culture]. Moscow: Progress-Traditsiya. Retrieved from http: //www.gumer.info > bibliotek_Buks > Culture > Heiz.

Shirokikh, E. A. (2015). Preczedentnyie fenomeny v angloyazychnom yumoristicheskom diskurse [Precedent phenomena in the English-language humorous discourse]. Vestnik Udmurtskogo Universiteta. Istoriya i Filologiya, 25, 145-150. 